ISSN: 1410-8917

Jurnal Kimia Sains \& Aplikasi

e-ISSN: 2597-9914

\section{Jurnal Kimia Sains dan Aplikasi Journal of Scientific and Applied Chemistry}

Journal homepage: http://ejournal.undip.ac.id/index.php/ksa

\title{
Synthesis of 4-Hydroxy-2-Methylchalcone from meta-Cresol Formilation Product and Its Activities as an Antibacteria
}

\author{
Ismiyarto $^{\mathrm{a},{ }^{*},}$, Suyanti ${ }^{\mathrm{a}}$, Purbowatiningrum Ria Sarjono ${ }^{\mathrm{a}}$, Ngadiwiyana $^{\mathrm{a}}$, Nor Basid Adiwibawa \\ Prasetya $^{a}$ \\ ${ }^{a}$ Chemistry Department, Faculty of Sciences and Mathematics, Diponegoro University, Jalan Prof. Soedarto, Tembalang, Semarang \\ * Corresponding author: ismiyarto@live.undip.ac.id \\ https://doi.org/10.14710/jksa.21.4.193-197
}

\section{Article Info}

Article history:

Received: 20 August 2018 Revised: 22 October 2018 Accepted: 23 October 2018 Online: 31 October 2018

Keywords:

Claisen-Schmidt, Chalcone, Reimer-

Tiemann, Antibacterial

\section{Kata Kunci:}

Claisen-Schmidt, Kalkon, Reimer-Tiemann, Antibakteri

\section{Abstract}

Research on the synthesis of 4-hydroxy-2-methylchalcone from 4-hidroksi-2metilbenzaldehida as formilated meta-cresol product and its antibacterial activity test has been conducted. As the first step, synthesis of 4-hydroxy-2-methylbenzaldehyde was carried out by treatment meta-cresol with chloroform through the Reimer-Tiemann formylation. Product is a brown solid with $23.94 \%$ yields. Furthermore, the 4 -hydroxy2-methylchalcone was synthesized using the 4-hydroxy-2-methylbenzaldehyde and acetophenone through the Claisen-Schmidt reaction. The product is a brownish yellow solid with $29.74 \%$ yields. Antibacterial test against Escherichia coli and Staphylococcus aureus bacteria was carried out by comparing the activity of 4-hydroxy-2methylchalcone with 4-hydroxy-3-methoxychalcone, and chalcone compounds. The antibacterial activity test showed that the 4-hydroxy-2-methylchalcone compound, 4hydroxy-3-methoxychalcone, and chalcone compounds gave a better antibacterial activity against Escherichia coli than the Staphylococcus aureus.

\section{Abstrak}

Telah dilakukan sintesis 4-hidroksi-2-metilkalkon dari 4-hidroksi-2metilbenzaldehida sebagai produk formilasi meta-kresol dan uji aktivitasnya sebagai antibakteri. Pada tahap pertama dilakukan sintesis 4-hidroksi-2-metilbenzaldehida dengan bahan dasar meta-kresol dan kloroform melalui reaksi formilasi ReimerTiemann menghasilkan padatan berwarna coklat dengan rendemen $23,94 \%$. Tahap selanjutnya adalah sintesis 4-hidroksi-2-metilkalkon menggunakan bahan dasar 4hidroksi-2-metilbenzaldehid dan asetofenon melalui reaksi Claisen-Schmidt menghasilkan padatan berwarna kuning kecoklatan dengan rendemen 29,74\%. Uji antibakteri terhadap bakteri Escherichia coli dan Staphylococcus aureus, dilakukan terhadap 4-hidroksi-2-metilkalkon dan dibandingkan dengan dua turunan senyawa kalkon yaitu: 4-hidroksi-3-metoksikalkon dan kalkon. Uji aktivitas antibakteri menunjukkan bahwa senyawa 4-hidroksi-2-metilkalkon, senyawa 4-hidroksi-3metoksikalkon, serta senyawa kalkon mempunyai aktivitas antibakteri yang lebih baik terhadap bakteri Escherichia coli daripada pada bakteri Staphylococcus aureus.

\section{Pendahuluan}

Senyawa kalkon $\left(\mathrm{C}_{15} \mathrm{H}_{12} \mathrm{O}\right)$ merupakan salah satu golongan flavonoid yang sangat penting di alam namun penyebarannya sangat terbatas dan hanya ditemukan pada beberapa golongan tumbuhan dengan jumlah yang sangat sedikit [1]. Hal ini disebabkan kalkon memiliki peranan penting dalam pembuatan turunan flavonoid karena berfungsi sebagai zat antara [2]. Menurut Gaikwad dkk. [3] dan Chavan dkk. [4], senyawa kalkon dan 
turunannya mempunyai beberapa aktivitas pharmasi seperti antibakteri, antikanker, antioksidan, serta anti inflamasi [3, 4].

Sintesis kalkon dapat dihasilkan melalui reaksi kondensasi aldol silang (Claisen-Schmidt) yang melibatkan aldehid aromatik dan alkil atau aril keton [5]. Aktivitas biologis kalkon dipengaruhi oleh gugus karbonil $\alpha, \beta$-tak jenuh dan subtituen yang terikat pada kedua cincin aromatic [6].

Kohler dan Chadwell [7] telah berhasil mensintesis senyawa kalkon yang paling sederhana, benzilidenasetofenon melalui mekanisme reaksi ClaisenSchmidt dengan katalis basa (NaOH 15\%). Bahan awal yang digunakan yaitu benzaldehid dan asetofenon. Selain itu, penelitian tentang kalkon juga telah dilakukan oleh Madiyono [8] dengan mensintesis senyawa 3-metoksi4-hidroksikalkon dari bahan awal vanilin dan asetofenon.

Pada penelitian dilakukan sintesis senyawa $4^{-}$ hidroksi-2-metilbenzaldehid melalui reaksi formilasi Reimer-Tiemann menggunakan meta-kresol. Senyawa 4hidroksi-2-metilbenzaldehid ini selanjutnya digunakan sebagai bahan dasar sintesis turunan kalkon melalui reaksi kondensasi aldol silang (Claisen-Schmidt).

Senyawa yang didapatkan kemudian akan dibandingkan sifat antibakterinya dengan senyawa 4hidroksi-3-metoksikalkon dan senyawa kalkon. Adanya gugus metil dan hidroksi pada senyawa turunan kalkon ini, diharapkan dapat memberikan aktivitas antibakteri yang lebih baik.

\section{Metode Penelitian}

Sintesis senyawa 4-hidroksi-2-metilbenzaldehid dilakukan melalui reaksi formilasi Reimer-Tiemann menggunakan meta-kresol. Hasil sintesis senyawa 4hidroksi-2-metilbenzaldehid kemudian digunakan sebagai bahan dasar sintesis 4-hidroksi-2-metilkalkon melalui reaksi Claisen-Schmidt. Identifikasi hasil sintesis dilakukan menggunakan FTIR, GC-MS, ${ }^{\mathrm{H}-\mathrm{NMR}}$, LC-MS, dan UV-Vis. Tahap terakhir yaitu uji aktivitas antibakteri Staphylococcus aureus $\left(\mathrm{G}^{+}\right)$dan Eschericia coli $\left(\mathrm{G}^{-}\right)$ menggunakan metode difusi cakram terhadap 4hidroksi-2-metilkalkon dan dibandingkan dengan 4hidroksi-3-metoksikalkon dan kalkon.

\subsection{Alat dan Bahan}

Alat: Seperangkat alat gelas, 1 set alat refluks, evaporator, pengaduk, TLC, kertas saring, kromatografi kolom gravitasi, autoklaf, inkubator, laminar air flow, GC-MS Perkin Elmer, FTIR, H-NMR (JEOL), LCMS-ESI pos ion, UV-Vis. Bahan: m-kresol, etanol teknis 96\%, etanol p.a, $\mathrm{NaOH}$, akuades, kloroform p.a, $\mathrm{HCl} 1 \mathrm{M}$, etil asetat p.a, etil asetat teknis, $\mathrm{Na}_{2} \mathrm{SO}_{4}$ anhidrat, silika gel 60 G, asetofenon, DMSO, plat KLT, metanol p.a, kertas saring, amoxicillin, agar, yeast, alkohol 70\%, pepton.

\subsection{Sintesis 4-hidroksi-2-metilbenzaldehida}

Larutan m-kresol (10 mmol) di dalam $10 \mathrm{~mL}$ etanol ditambahkan $3 \mathrm{~g} \mathrm{NaOH}$ (75 mmol) dalam $15 \mathrm{~mL}$ air. Campuran reaksi direfluks pada suhu $80^{\circ} \mathrm{C}$. Sesudah reaksi berlangsung 5 menit, $30 \mathrm{~mL}$ kloroform ditambahkan secara perlahan. Pengadukan dilanjutkan selama 1 jam sesudah penambahan kloroform selesai. Pelarut etanol kemudian diuapkan dengan evaporator dan 1 M HCl ditambahkan untuk menetralkan kelebihan $\mathrm{NaOH}$ hingga $\mathrm{pH}=2-3$. Larutan selanjutnya diekstraksi dengan etilasetat sebanyak 3 kali. Selanjutnya fraksi etilasetat dikeringkan dengan $\mathrm{Na}_{2} \mathrm{SO}_{4}$ anhidrat dan selanjutnya dilakukan evaporasi. Residu selanjutnya dimurnikan dengan Kromatografi Kolom Gravitasi menggunakan silika gel untuk menghasilkan produk dengan kemurnian tinggi.9 Analisis produk dilakukan menggunakan GC-MS dan ${ }^{\mathrm{H}-\mathrm{NMR}}$.

\subsection{Sintesis Senyawa 4-hidroksi-2-metilkalkon}

Senyawa 2-metil-4-hidroksi benzaldehid $1 \mathrm{~g}$ (7,34 mmol) dilarutkan ke dalam 6,80 $\mathrm{mL}$ etanol $96 \%$. Pelarutan dilakukan dengan menggunakan pengaduk magnetik. Asetofenon 0,857 mL (7,34 mmol) dan 4,50 mL $\mathrm{NaOH} 60 \%$ ditambahkan. Campuran dipanaskan pada suhu $60^{\circ} \mathrm{C}$ selama 3 jam. Monitoring TLC dilakukan dengan perbandingan eluen etil asetat: n-hexana 1:3. Hasil reaksi dievaporasi pada suhu $45^{\circ} \mathrm{C}$, kemudian diasamkan dengan $\mathrm{HCl} 1 \mathrm{M}$ hingga $\mathrm{pH}=1$. Ekstraksi hasil evaporasi dilakukan dengan penambahan etil asetat 30 $\mathrm{mL}$ sebanyak 3 kali. Fraksi etil asetat dipisahkan kemudian dikeringkan dengan penambahan $\mathrm{Na}_{2} \mathrm{SO}_{4}$ anhidrat. Penyaringan dan evaporasi dilakukan hingga semua etil asetat menguap. Pemurnian menggunakan kromatografi kolom gravitasi dengan silika gel untuk mendapatkan produk yang diinginkan. Analisis produk dilakukan menggunakan UV-Vis, FTIR, dan LC-MS.

\subsection{Uji Aktivitas Antibakteri}

\subsubsection{Pembuatan Media Nutrient Agar (NA)}

Media agar dibuat dengan cara melarutkan 2,64 gram serbuk nutrient agar ke dalam $120 \mathrm{~mL}$ akuades. Campuran diaduk dan dipanaskan hingga mendidih. Media yang sudah mendidih tersebut disterilisasi menggunakan autoklaf pada suhu $121^{\circ} \mathrm{C}$ selama 15 menit.

\subsubsection{Pembuatan Stok Kultur Bakteri S. aureus dan $E$. coli}

Masing-masing koloni bakteri S. aureus dan E. coli diambil menggunakan jarum ose yang telah steril. Goresan bakteri ditanamkan pada NA dengan cara menggores. Inkubasi dalam incubator dilakukan pada suhu $37^{\circ} \mathrm{C}$ selama $18-24$ jam.

\subsubsection{Penyiapan Inokulum Bakteri}

Dari stok bakteri yang telah diinkubasi selama 24 jam, diambil satu gores enggunakan jarum ose yang telah steril. Goresan bakteri disuspensikan ke dalam $10 \mathrm{~mL}$ 
larutan $\mathrm{NaCl}$ 0,9\%. Suspensi bakteri kemudian diukur absorbansinya pada panjang gelombang $580 \mathrm{~nm}$ dan diencerkan dalam media $\mathrm{NaCl}$ sampai didapat kekeruhan suspense bakteri sama dengan kekeruhan larutan standard skala 0,5 Mc.Farland.

\subsubsection{Pembuatan Larutan Uji}

Dilakukan pengenceran terhadap produk hasil sintesis menggunakan DMSO untuk mendapatkan konsentrasi yang akan diujikan.

\subsubsection{Uji Aktivitas Antibakteri dengan Metode Difusi Cakram}

Sebanyak $15 \mathrm{~mL}$ media nutrient agar dituang ke dalam cawan petri dan dibiarkan memadat. Sebanyak 0,1 $\mathrm{mL}$ suspense bakteri yang telah diencerkan diinokulasikan ke nutrient agar yang telah memadat. Selanjutnya, kertas cakram yang telah ditempelkan pada permukaan media agar yang telah diberi bakteri, diteteskan sebanyak $15 \mu \mathrm{L}$ senyawa hasil. Dalam penelitian ini, ampisilin digunakan sebagai kontrol positif dan DMSO digunakan sebagai kontrol negatif. Media uji yang telah siap diinkubasi dalam incubator pada suhu $37^{\circ} \mathrm{C}$. Pengukuran diameter daerah hambatan pertumbuhan bakteri disekitar cakram kertas dilakukan pada waktu inkubasi jam ke 3, 6, 9, 18 dan 24 .

\section{Hasil dan Pembahasan}

\subsection{Sintesis 4-hidroksi-2-metilbenzaldehid}

Tahap ini dilakukan dengan mereaksikan $50 \mathrm{mmol}$ meta-kresol yaitu senyawa turunan fenol sebagai bahan utama sintesis 4-hidroksi-2-metilbenzaldehid dengan kloroform, $\mathrm{NaOH}$ serta etanol melalui metode refluks. Hasil reaksi selanjutnya dievaporasi untuk menguapkan pelarutnya yaitu etanol. Selanjutnya dilakukan ektraksi menggunakan kloroform. Terdapat 2 lapisan yaitu lapisan bawah berupa kloroform + hasil sintesis sedangkan lapisan atas berupa fraksi air. Monitoring TLC dilakukan pada lapisan bawah menggunakan eluen etil asetat: n-hexana (1: 3), profil TLC terdapat pada gambar 1 (4 noda). Tahap selanjutnya yaitu evaporasi pada fraksi bawah untuk menguapkan kloroform.

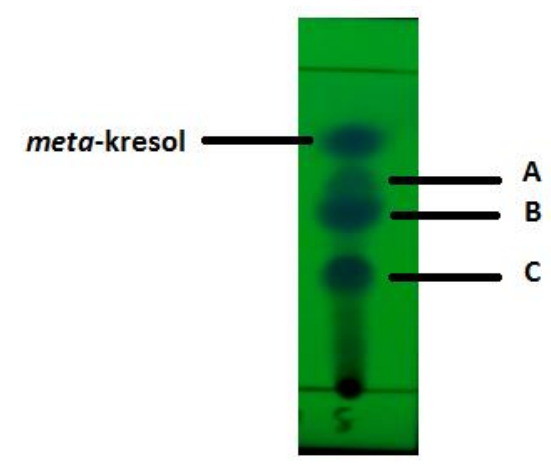

Gambar 1. Profil TLC dengan eluen etil asetat: n-hexana (1: 3) senyawa hasil reaksi melalui reaksi formilasi Reimer-Tiemann

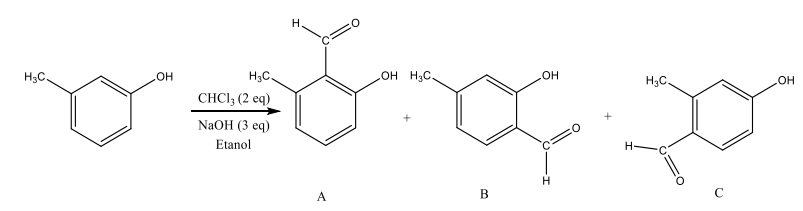

Gambar 2. Reaksi umum sintesis 4-hidroksi-2metilbenzaldehid

Reaksi reaksi formilasi Reimer-Tiemann secara umum dapat dilihat pada gambar 2. Analisis campuran produk menggunakan GC-MS bertujuan untuk mengetahui kelimpahan masing-masing fraksi dalam senyawa hasil reaksi. Hasil analisis komposisi senyawa hasil reaksi Reimer-Tiemann menggunakan meta-kresol terdapat pada tabel 1.

Tabel 1. Analisis komposisi senyawa hasil reaksi ReimerTiemann menggunakan meta-kresol

\begin{tabular}{ccccc}
\hline No. & Nama Senyawa & $\begin{array}{c}\text { Waktu } \\
\text { Retensi } \\
(\text { menit })\end{array}$ & $\begin{array}{c}\text { Massa } \\
\text { Molekul } \\
(\mathrm{M}+, \\
\text { g/mol) }\end{array}$ & $\begin{array}{c}\text { Kelimpahan } \\
(\%)\end{array}$ \\
\hline 1. & meta-kresol & 13,80 & 108 & 36 \\
2. & $\begin{array}{c}\text { 2-metil } \\
\text { salisilaldehid (A) }\end{array}$ & 15,46 & 136 & 9 \\
3. & $\begin{array}{c}\text { 4-metil } \\
\text { salisilaldehid (B) } \\
\text { 4-hidroksi-2- }\end{array}$ & 16,44 & 136 & 10 \\
metilbenzaldehid \\
(C)
\end{tabular}

Pemurnian noda ke-4 atau Noda C [1] dilakukan menggunakan kromatografi kolom cepat dengan eluen n-hexana: etil asetat. Produk yang dihasilkan berupa padatan coklat dengan rendemen $23.94 \%$. Berdasarkan data ${ }^{\mathrm{H}-\mathrm{NMR}}$ dari produk pada gambar 3 menunjukkan pergeseran kimia dengan nilai yang identik dengan 4hidroksi-2-metilbenzaldehid. Spektrum pada gambar 3 terdapat 8 puncak yang menunjukkan adanya senyawa $\mathrm{C}$. Pergeseran kimia $(\delta)$ 10,385 ppm dengan pemecahan singlet menunjukkan proton yang terikat pada gugus hidroksil. Pergeseran kimia ( $\delta)$ 9,904 ppm dengan pemecahan singlet menunjukkan proton yang terikat pada gugus aldehid. Pergeseran kimia ( $\delta$ ) 7,571-7,588 ppm dengan pemecahan duplet memiliki nilai $\mathrm{J}=8,5 \mathrm{~Hz}$ yang menunjukkan bahwa proton pada pergeseran kimia tersebut mengalami kopling dengan 1 proton lainnya pada posisi orto, pergeseran kimia ( $)$ (6,665-6,687 ppm dengan pemecahan duplet memiliki nilai $\mathrm{J}=8,5 \mathrm{~Hz}$ yang menunjukkan bahwa proton pada pergeseran kimia tersebut mengalami kopling dengan 1 proton lainnya pada posisi orto, dan pergeseran kimia ( $\delta$ ) 6,593 ppm dengan pemecahan singlet, ketiga pergeseran kimia tersebut menunjukkan adanya proton yang terikat pada cincin aromatik. Pergeseran kimia ( $\delta$ ) 2,438 ppm dengan pemecahan singlet menunjukkan adanya proton yang terikat pada gugus metil. 


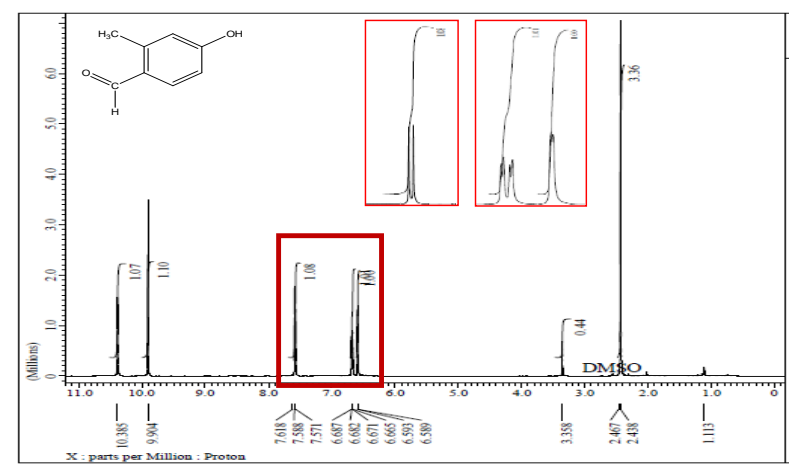

Gambar 3. Hasil analisis ${ }^{\mathrm{H}-\mathrm{NMR}}$ fraksi-4 senyawa

\subsection{Sintesis 4-hidroksi-2-metilkalkon}

Penelitian ini dilakukan dengan mereaksikan 4hidroksi-2-metilbenzaldehid dan asetofenon pada kondisi basa pekat ( $\mathrm{NaOH} 60 \%$ ) dan suhu $60^{\circ} \mathrm{C}$, kemudian dilakukan monitoring reaksi menggunakan TLC dengan eluen etil asetat: $n$-hexana $=1$ : 3 . Hasil monitoring TLC terdapat pada gambar 4 .

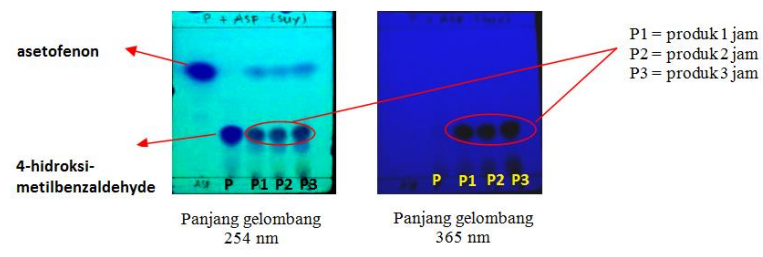

Gambar 4. Monitoring TLC reaksi 4-hidroksi-2metilkalkon

Hasil reaksi kemudian dievaporasi untuk menguapkan pelarut etanol dan setelah itu dilanjutkan dengan ekstraksi menggunakan etil asetat. Hasil ektraksi terdapat 2 lapisan yaitu fraksi air dan fraksi etil asetat, kemudian fraksi etil asetat dilakukan evaporasi untuk menguapkan etil asetat. Hasil evaporasi kemudian dilakukan pemurnian dengan kromatografi kolom gravitasi menggunakan eluen etil asetat dan n-hexana. Hasil pemurnian ini kemudian dilakukan evaporasi untuk menguapkan eluennya. Rendemen yang didapatkan setelah dievaporasi burupa padatan berwarna kuning kecoklatan sebesar 0,52 g dengan rendemen 29,74\%. Reaksi secara umum terdapat pada Gambar 5.

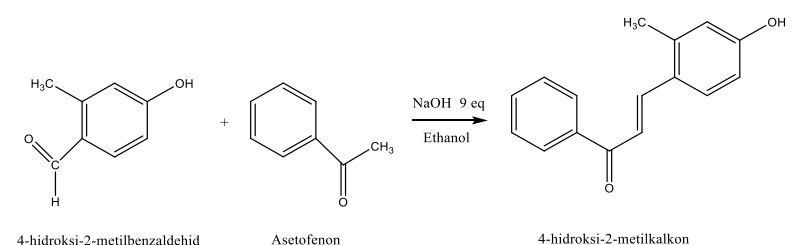

Gambar 5 Reaksi umum sintesis 4-hidroksi-2metilkalkon

Analisis produk dilakukan menggunakan spektrofotometer UV-Vis seperti pada Gambar 6 menunjukkan adanya 2 puncak yang merupakan ciri khas dari senyawa kalkon yaitu pada daerah panjang gelombang $272 \mathrm{~nm}$ dan $353 \mathrm{~nm}$. Puncak serapan pada panjang gelombang $272 \mathrm{~nm}$ menunjukkan adanya sistem benzoil sedangkan puncak serapan pada panjang gelombang $353 \mathrm{~nm}$ menunjukkan adanya sistem sinamoil.

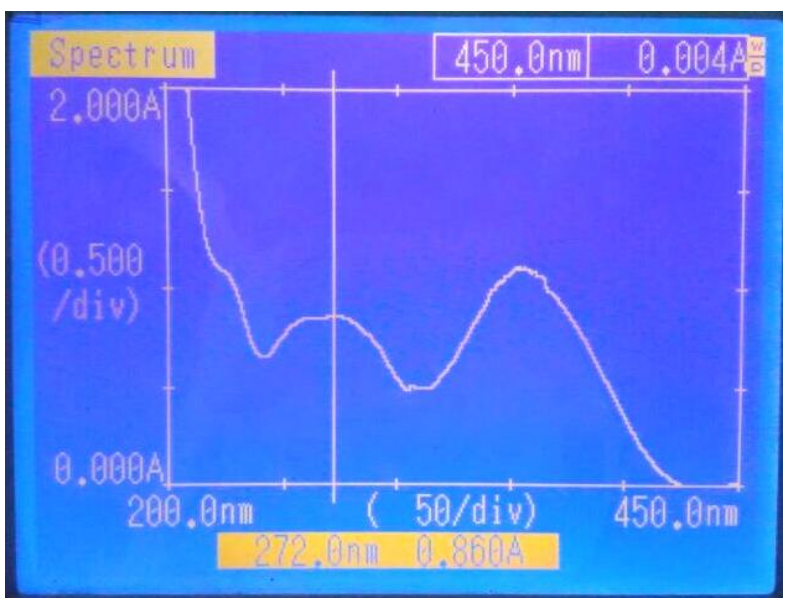

Gambar 6. Hasil spektra UV-Vis senyawa 4-hidroksi-2metilkalkon

Analisis selanjutnya menggunakan instrumen FTIR yang memberikan informasi tentang gambaran gugus fungsi dari senyawa yang dianalisis. Hasil spektra FTIR terdapat pada gambar 7 .

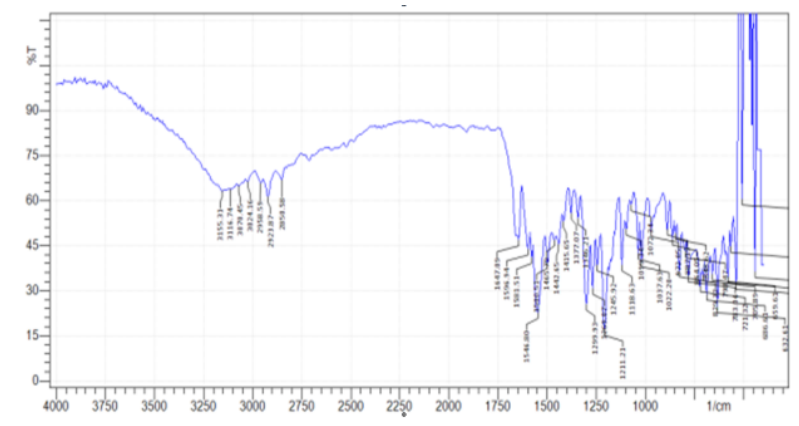

Gambar 7 Spektra FTIR senyawa 4-hidroksi-2metilkalkon

Hasil analisis pada Gambar 7 di atas, terdapat puncak pada bilangan gelombang yang dilaporkan pada Tabel 2.

Tabel 2. Interpretasi spektra FTIR senyawa 4-hidroksi2-metilkalkon

\begin{tabular}{ccc}
\hline No. & $\begin{array}{c}\text { Bilangan } \\
\text { gelombang }\left(\mathrm{cm}^{-}\right. \\
1)\end{array}$ & Keterangan \\
\hline 1 & 3155,31 & $(-\mathrm{OH})$ \\
2 & 3024,16 & $(\mathrm{C}-\mathrm{H}$ ulur aromatik) \\
3 & 2923,87 & $\left(\mathrm{C}-\mathrm{H} \mathrm{sp}^{3}\right)$ \\
4 & 1647,09 & $(\mathrm{C}=$ O terkonjugasi dengan \\
cincin aromatik $)$ \\
5 & 1546,80 & $(\mathrm{C}=\mathrm{C}$ tekuk aromatik) \\
6 & 1377,07 & Gugus alkil $\left(\mathrm{CH}_{3}\right)$ \\
\hline
\end{tabular}

Analisis selanjutnya yaitu identifikasi menggunakan instrumen LC-MS yang dapat memberikan informasi 
kemurnian dan berat molekul dari senyawa 4-hiroksi-2metilkalkon. Hasil analisis LC-MS disajikan pada gambar 8.

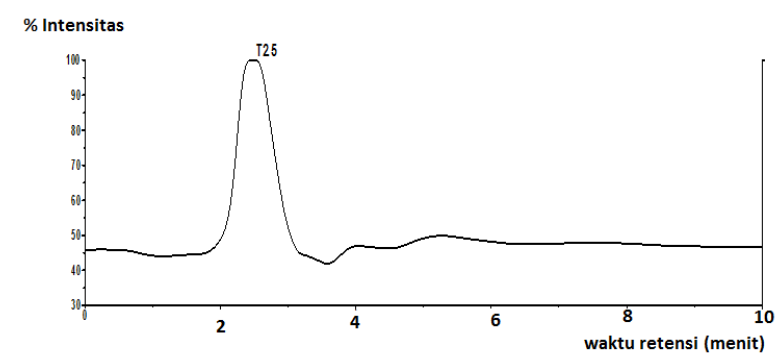

Gambar 8. Kromatogram LC senyawa 4-hidroksi-2metilkalkon

Hasil kromatogram LC pada Gambar 9 menunjukkan adanya satu puncak tertinggi dengan waktu retensi 2,5 menit yang artinya bahwa senyawa yang dihasilkan murni. Data spektogram pada Gambar 9 menunjukkan bahwa muncul puncak dengan $\left[\mathrm{M}^{+} \mathrm{H}^{+}\right] \quad 239,21 \mathrm{~m} / \mathrm{z}$ sehingga dapat disimpulkan bahwa berat molekul 238 $\mathrm{g} / \mathrm{mol}$ adalah sesuai dengan berat molekul senyawa 4hidroksi-2-metilkalkon.

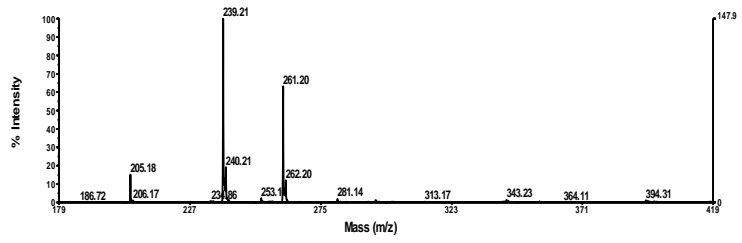

Gambar 9 Spektogram massa senyawa 4-hidroksi-2metilkalkon

\subsection{Uji Antibakteri}

Uji antibakteri dilakukan terhadap 3 senyawa dengan kontrol (+) dan (-) pada konsentrasi yang sama yaitu 4000 ppm (tabel 3).

Tabel 3. Hasil pengukuran luas zona hambat terhadap bakteri Staphylococcus aureus dan Eschericia coli

\begin{tabular}{ccc}
\hline \multirow{2}{*}{$\begin{array}{c}\text { Larutan Uji (4000 } \\
\text { ppm) }\end{array}$} & \multicolumn{2}{c}{ Luas Zona Hambat (mm) } \\
\cline { 2 - 3 } & E. coli & S. aureus \\
\hline $\begin{array}{c}\text { 4-hidroksi-2- } \\
\text { metilkalkon (A) }\end{array}$ & 2,2 & 1,6 \\
$\begin{array}{c}\text { 4-hidroksi-3- } \\
\text { metoksikalkon (B) }\end{array}$ & 1,6 & 1,5 \\
Kalkon (C) & 0,8 & 0,8 \\
kontrol positif (+) & 9,5 & 8,8 \\
kontrol negatif (-) & 0 & 0 \\
\hline
\end{tabular}

\section{Kesimpulan}

Senyawa 4-hidroksi-2-metilbenzaldehid telah berhasil disintesis dari bahan dasar meta-kresol dan kloroform melalui reaksi formilasi Reimer-Tiemann dengan rendemen sebesar 23,94\% dan berbentuk padatan berwarna coklat. Senyawa 4-hidroksi-2metilkalkon telah berhasil disintesis melalui reaksi
Claisen-Schmidt dari bahan dasar 4-hidroksi-2metilbenzaldehid dan asetofenon dengan rendemen sebesar 29,74\% dan berbentuk padatan berwarna kuning kecoklatan. Senyawa 4-hidroksi-2-metilkalkon, senyawa 4-hidroksi-3-metoksikalkon, dan senyawa kalkon memiliki aktivitas antibakteri yang lebih baik terhadap bakteri Escherichia coli daripada Staphylococcus aureus.

\section{Ucapan Terimakasih.}

Penulis mengucapkan terima kasih kepada Universitas Diponegoro atas dukungan dana melalui Hibah Penelitian RPP (RISET PENGEMBANGAN DAN PENERAPAN) Bacth 2, Tahun 1 (2018) (No:47430/UN7.P4.3/2018) Universitas Diponegoro

\section{Daftar Pustaka}

[1] M. Hapsari, Tri Windarti, Purbowatiningrum Ria Sarjono, Ngadiwiyana, Ismiyarto, Synthesis of 4hydroxy-3-methylchalcone from Reimer-Tiemann reaction product and its antibacterial activity test, IOP Conference Series: Materials Science and Engineering, 349, 1, (2018) 012036 https://doi.org/10.1088/1757-899X/349/1/012036

[2] Rajat Ghosh, Abhijit Das, Synthesis and biological activities of chalcones and their heterocyclic derivatives: a review, World Journal of Pharmacy and Pharmaceutical Sciences, 3, 3, (2014) 578-595

[3] Kishor V Gaikwad, Sandip V Gaikwad, Satish B Jadhav, Shantilal D Rathod, Synthesis of some novel chalcones of phthalimidoester possessing good antiinflammatory and antimicrobial activity, Indian Jurnal of Chemistry, 49B, (2010) 131-136

[4] B. B. Chavan, A. S. Gadekar, P. P. Mehta, P. K. Vawhal, A. K. Kolsure, A. R. Chabukswar, Synthesis and Medicinal Signifiance of Chalcones- A Review, Asian Journal of Biomedical and Pharmaceutical Sciences, 6, $56,(2016) 1-7$

[5] Hery Suwito, Jumina, Mustofa, Alfinda Novi Kristanti, Ni Nyoman Tri Puspaningsih, Chalcones: Synthesis, structure diversity and pharmacological aspects, Journal of Chemical and Pharmaceutical Research, 6, 5, (2014) 1075-1088

[6] V. M. Kamble, G. D. Hatnapure, A. P. Keche, S. Birajdar, S. G. Patil, R. H. Tale, A. H. Rodge, S. S. Turkar, K. Gour, Synthesis and biological evaluation of a novel series of methoxylated chalcones as antioxidant and anti-microbial agents, Journal of Chemical and Pharmaceutical Research, 3, 6, (2011) 639-648

[7] E. P. Kohler, H. M. Chadwell, Organic Syntheses, in, 1941.

[8] Madiyono, Sintesis Senyawa 4-hidroksi-3metoksikalkon dari Vanilin dan Asetofenon, Departemen Kimia, Universitas Diponegoro, Semarang 